\title{
Negligência urbanística e projeto urbano na Cidade do Rio de Janeiro.
}

\author{
Henrique Barandier \\ Arquiteto e Urbanista, Doutor em Urbanismo, Coordenador Técnico do \\ Instituto Brasileiro de Administração Municipal (IBAM).
}

\section{RESUMO}

Este artigo trata da noção de negligência urbanística, concebida a partir de estudos sobre 0 desenvolvimento urbano carioca e sobre a prática de projetos urbanos na cidade do Rio de Janeiro nas últimas três décadas. Parte-se da hipótese de que, no Rio de Janeiro, subjaz um quadro de negligência urbanística que se impõe de diferentes formas sobre o território, em especial, pelas tendências de segregação socioespacial e de reprodução de padrões insustentáveis de urbanização determinadas por dois fenômenos principais: dispersão urbana e informalidade urbana crescentes

Ao mesmo tempo, observa-se que a prática de projetos urbanos, privilegiada na gestão urbana carioca, não rompeu com o urbanismo normativo tradicional, que, do ponto de visto teórico, a noção de projeto urbano se contraporia, nem com lógicas que orientam o desenvolvimento urbano desigual e excludente na cidade.

PALAVRAS-CHAVE: Negligência urbanística; Projeto urbano; Rio de Janeiro.

\section{ABSTRACT}

This article is about the notion of urban negligence, conceived through the studies of the Carioca urban development and the practice of urban projects in the city of Rio de Janeiro in the last three decades. It starts from the hypothesis that, in Rio de Janeiro, there is a framework of urban negligence that imposes itself in different forms on the territory, mostly, for tendencies of sociospatial segregation and the reproduction of unsustainable urbanization patterns determined by two main phenomenons: urban dispersion and urban informality in growth.

At the same time, it's seen that the practice of urban projects, privileged in the Carioca urban management, did not break apart from the traditional normative urbanism which, from a theoretical point of view, the notion of the urban project would oppose, nor with the ideas that guide the unequal and excluding urban development in the city.

KEY-WORDS: Urban negligence; Urban project; Rio de Janeiro.

\section{Introdução}

O presente artigo trata da noção de "negligência urbanística", concebida a partir de estudos sobre o desenvolvimento urbano carioca e sobre a prática de projetos urbanos na cidade do Rio de Janeiro nas últimas três décadas, elaborados no âmbito da tese de doutorado deste autor. A hipótese principal que orientou a pesquisa é que no Rio de Janeiro subjaz um quadro de negligência urbanística que se impõe de diferentes formas sobre o território, em especial, pelas tendências de segregação socioespacial e de reprodução de padrões

1 Este artigo baseia-se na tese de doutorado deste autor, também intitulada "Negligência Urbanística e Projeto Urbano na Cidade do Rio de Janeiro”. A tese foi desenvolvida no Programa de Pós-graduação em Urbanismo da Universidade Federal do Rio de Janeiro (PROURB) e aprovada em 2015, contando com apoio financeiro do CNPq, para desenvolvimento da pesquisa no Brasil, e da CAPES, no período de estágio no exterior. 
insustentáveis de urbanização determinadas por dois fenômenos principais: dispersão urbana e informalidade urbana crescente.

No percurso teórico-metodológico adotado na pesquisa se buscou confrontar a prática de projetos urbanos com as tendências estruturantes do desenvolvimento urbano da cidade, identificando como, ao longo do tempo, se alteram significados e formatos dos projetos urbanos. Nesse contexto, se observa que a prática de projetos urbanos no Rio de Janeiro não rompeu com o urbanismo normativo tradicional, que, do ponto de visto teórico, a noção de projeto urbano se contraporia. Ao mesmo tempo e talvez por isso mesmo, também não rompeu com lógicas que orientam o desenvolvimento urbano desigual e excludente na cidade. Nota-se assim que, alimentando o próprio quadro de negligência urbanística em suas diferentes dimensões, a prática de projetos urbanos no Rio de Janeiro tem se configurado de forma desvinculada da revisão do aparato normativo e instrumental de gestão urbana - de tradição elitista, tecnocrática e burocrática -, sendo muito mais determinada pelo perfil e prioridades de cada prefeito do que pela constituição de uma cultura de projetos urbanos relacionada a processos continuados de discussão sobre a cidade, permeáveis às diferentes visões e disputas que fazem parte da construção democrática.

O artigo está estruturado em três seções. A primeira apresenta a abordagem conceitual da noção de negligência urbanística, núcleo central da pesquisa, que a nosso ver se mostra válida para entendimento de diferentes realidades. A segunda seção trata da dinâmica urbana recente da cidade do Rio de Janeiro, com foco nos fenômenos da dispersão e da informalidade urbanas que a caracterizam. Por fim, na última seção, são descritas, sucintamente, o que no desenvolvimento da pesquisa caracterizamos como três gerações de projetos urbanos no Rio de Janeiro: a primeira, dos anos 1980, relacionada ao contexto de redemocratização do país; a segunda, desenvolvida nos anos 1990 num ambiente de oposição entre a agenda da reforma urbana e a agenda neoliberal para as cidades; e a terceira, iniciada nos anos 2000 e marcada pela realização de grandes eventos esportivos internacionais no Rio de Janeiro com suas promessas de legado urbano.

\section{Negligência Urbanística: abordagem conceitual}

O cenário de vastas áreas de urbanização precária que caracteriza as cidades brasileiras, sobretudo as grandes metrópoles é desolador. A informalidade urbana estrutural já bem descrita na nossa literatura, ao mesmo tempo resultado e produtora de desigualdades, expõe a contraposição entre a cidade em grande parte autoconstruída, muitas vezes em áreas inadequadas à ocupação urbana, e a cidade produzida pelo mercado imobiliário formal de acordo (mas nem sempre) com as normas urbanísticas e dirigida às classes sociais mais favorecidas. Nesse contexto, observa-se que diferentes formas de negligência urbanística permeiam as práticas de gestão nas cidades brasileiras e se expressam fisicamente, sobretudo, nas desigualdades territoriais, muitas vezes fomentadas pela ação pública ou por omissões do Estado.

A palavra negligência, no seu sentido mais geral, remete à ideia de descuido, de desatenção. Ou seja, negligenciar uma determinada questão seria como que descuidar-se dela. Desleixo, descuido (ou falta de cuidado), incúria, desatenção (ou falta de atenção) e preguiça tanto para o "Dicionário Aurélio" como para o "Dicionário Houaiss" ${ }^{3 "}$ são termos que podem ter

2 “Novo Aurélio Século XXI: o dicionário da língua portuguesa”, 3a ed., 1999. Negligência. [Do lat. negligentia.] S.f. 1. Desleixo, descuido, incúria. 2. Desatenção, menoscabo, menosprezo. 3. Preguiça, indolência. (Cf. negligencia, do v. negligenciar).

3 Grande Dicionário Houaiss da Língua Portuguesa” (edição on-line: http://houaiss.uol.com.br/). Negligência. substantivo feminino ( sXIV). 1. falta de cuidado; incúria > trata a casa e a família com muita n. > 2. falta de apuro, de atenção; desleixo, desmazelo < veste-se com n. > 3. falta de interesse, de motivação; indiferença, preguiça < n. no trabalho leva ao desemprego > 4. jur. inobservância e descuido na execução de ato. 
o sentido de negligência. O "Aurélio" remete também à "indolência", palavra que, segundo o próprio dicionário, pode ter o sentido de "insensibilidade". Já o "Houaiss" inclui entre os significados de "negligência" o termo "indiferença". Pensando nos fenômenos urbanos, muitos dos quais têm sido facilmente naturalizados, ou tratados como inexoráveis, e sobre práticas urbanísticas desenraizadas, as noções de insensibilidade e indiferença parecem úteis para se compreender posturas negligentes no campo do planejamento urbano e do urbanismo. Assim, é possível considerar que para além do sentido de omissão, mais claramente associado ao termo negligência, a noção de "negligência urbanística" se situa entre a insensibilidade e a indiferença em relação ao espaço urbano, à cidade e ao processo de urbanização.

Do ponto de vista jurídico, destaca-se, o termo negligência implica na ideia de responsabilidade e está vinculado a condutas esperadas de cada sujeito. Sendo assim, seja pela ação, seja pela inação, condutas negligentes de uns podem ter consequências para si mesmos e para outros. A ideia de responsabilidade, por sua vez, conduz a interrogações sobre quem são os agentes da negligência urbanística. Certamente, se poderia falar da negligência urbanística presente na ação de diferentes atores sociais na cidade, entendendo, num sentido amplo, que todos têm responsabilidades na construção do espaço urbano. Porém, a obrigação do Estado de garantir direitos sociais, seu poder regulador e sua capacidade de intervenção por meio da realização de obras públicas, que em tese deveriam atender aos interesses da coletividade, fazem dele um ator maior e central para a formulação conceitual aqui pretendida.

As formas de negligência urbanística podem ser múltiplas e difíceis de serem caracterizadas de modo objetivo, pois dizem respeito às diferentes escalas do fenômeno urbano, aos processos de produção e reprodução das cidades, às formas de intervir no espaço urbano, aos papéis desempenhados pelos diversos atores urbanos, aos sistemas de valores que organizam a sociedade etc.

No entanto, elas são reconhecíveis. E quando se trata de um país como o Brasil, em que a modernização incompleta não garantiu padrão de urbanização adequado a grande parte das áreas urbanas e, mais do que isso, contribuiu para produzir desigualdades nas cidades, a noção de negligência urbanística revela-se mais do que apropriada. As extensas áreas ocupadas por favelas e outros tipos de assentamentos precários presentes em todas as grandes cidades brasileiras e também em muitas, talvez a maioria, das médias e pequenas são a expressão incontestável dessa realidade. E não se trata apenas da herança de um processo de urbanização acelerado no século XX, mas resultado da lógica do desenvolvimento urbano que continua a produzir desigualdades e disfunções espaciais.

Nas palavras de Maricato (2000), trata-se de um processo de urbanização que "segrega e exclui" e que se caracteriza, de modo geral, pela dispersão urbana descontínua - que deixa vazios no interior da malha urbana e produz o esvaziamento de áreas consolidadas - combinada com a ocupação de áreas ambientalmente frágeis, insuficiência de infraestrutura e serviços urbanos, habitações precárias autoconstruídas e informalidade crescente.

Apesar dos avanços institucionais e jurídicos no campo das questões urbanas desde a redemocratização do país, com a Constituição Federal de 1988, com o Estatuto da Cidade e diversos outros marcos legais, as mudanças nas práticas de gestão são lentas, marcadas por avanços e recuos, ambiguidades, contradições e disputas. E não necessariamente caminham no sentido de construção de cidades mais inclusivas. É bem esse o cenário que marcou o final da década de 2000 e a primeira metade desta, quando, em meio a uma nova onda desenvolvimentista no país, as formas de segregação urbana se renovaram, impulsionadas pela própria ação pública e pelas renovadas associações entre poder púbico e forças econômicas nas cidades.

E é nesse sentido que a noção de negligência se mostra ainda mais pertinente para reflexão sobre o momento atual, pois além de haver conhecimento acumulado sobre as 
questões urbanas, particularmente sobre o problema da desigualdade-informalidadeprecarieade, há hoje instrumentos incorporados ao ordenamento jurídico que possibilitam novas formas de ação, particularmente dos municípios. Evidentemente, esse quadro é determinado em grande parte por interesses econômicos poderosos, estratégias políticas, posições ideológicas, que se entrelaçam num quadro de negligência urbanística que, como já assinalado anteriormente, permeia a gestão urbana.

Buscando entender como esse quadro de negligência urbanística se configura, podemos pensá-lo a partir de três dimensões principais: a) uma que é estrutural, porque diz respeito a como e em que o Estado fundamenta sua ação em relação à cidade; b) outra que é operacional, pois relacionado ao instrumental utilizado pelo poder público, em particular o município, no controle urbanístico; c) e finalmente uma terceira que é projetual, relacionada ao papel dos projetos urbanos na configuração e reconfiguração dos espaços da cidade.

O quadro de exclusão territorial das cidades brasileiras sugere uma primeira dimensão da negligência urbanística que é estrutural. Ou seja, a própria lógica de urbanização é negligente em relação ao tipo de cidade que dela resulta. Ribeiro e Santos Junior (2012) explicam que:
A cidade brasileira contemporânea resulta da combinação de dois mecanismos complementares: a liberdade para os agentes capitalistas tratarem e negociarem a cidade (em especial a moradia e o solo urbano) como mercadoria (ou seja, a livre mercantilização) e a perversa política de tolerância com todas as formas de uso e apropriação do solo urbano (o que permitiu não somente as ocupações ilegais das favelas e loteamentos irregulares, mas também as formas ilegais de ocupação de áreas nobres pelas classes médias e pelas elites). (RIBEIRO; SANTOS JUNIOR, 2012. p.13).

Os dois mecanismos apontados pelos autores são reveladores do modo como as cidades brasileiras se estruturam, tendo o Estado como o principal agente:

Protegendo os interesses da acumulação urbana (proveniente da produção da cidade) da concorrência de outros circuitos, seja realizando encomendas de construção de vultosas obras urbanas, ou ainda pela omissão em seu papel de planejador do crescimento urbano. (RIBEIRO; SANTOS JUNIOR, 2012. p.13)

A omissão do Estado em relação ao que deveria ser o seu papel de garantir a construção da cidade equilibrada e equitativa, ou seja, a negligência urbanística do Estado, produziu cidades que, ainda segundo os mesmos autores, são "inacabadas, pois estas são incapazes de mediar os conflitos e integrar, mesmo que parcialmente, as distintas classes e grupos sociais" (RIBEIRO; SANTO JUNIOR, 2012. p.14).

No centro dessa questão está o problema da terra, do "nó da terra" na sociedade brasileira como enfatiza Maricato (2011). Carlos Nelson dizia que quando perguntam qual o maior problema urbano brasileiro, "nem é preciso pensar duas vezes: É a terra!" (SANTOS, 1986). Décadas depois, o problema central ainda continua o mesmo, apesar do enorme avanço que representou a Constituição Federal de 1988 afirmar a função social da propriedade urbana e, uma dezena de anos depois, o Estatuto da Cidade consagrar diversos instrumentos que podem, dependendo de como forem utilizados, ao menos contribuir para favorecer o acesso à terra urbanizada.

A negligência urbanística estrutural conduz a outra dimensão da negligência urbanística que é operacional, que diz respeito aos instrumentos utilizados pela sociedade, por meio do Estado, para regular a cidade. A legislação urbanística e o aparato estatal para garantir sua aplicação, que supostamente cumpririam esse papel, no entanto, compreendem uma série de mecanismos que acabam também por promover injustiças espaciais. O modelo estático de regulação urbana, que tem no instrumento do zoneamento funcional seu maior expoente, produziu um sistema normativo, ainda hoje arraigado em boa parte dos 
municípios brasileiros, baseado em idealizações tecnocráticas e que jamais conseguiu dar conta da complexidade da urbanização desigual das cidades brasileiras.

De acordo com Rolnik, é preciso compreender que mais "do que definir formas de apropriação do espaço permitidas ou proibidas, mais do que efetivamente regular a produção da cidade, a legislação urbana age como marco delimitador de fronteiras de poder." (Rolnik, 1999. p.13). Nesse sentido, a legislação pode ser entendida como instrumento que, contraditoriamente, nega o acesso pleno à cidade para uma parte significativa da população, pois, ainda segundo a mesma autora, ela apenas

aparentemente funciona, como uma espécie de molde da cidade ideal ou desejável. Entretanto (...) ela delimita [para a maior parte das cidades latinoamericanas, provavelmente] apenas a menor parte do espaço construído, uma vez que o produto - cidade - não é fruto da aplicação inerte do próprio modelo contido na lei, mas da relação que esta estabelece com as formas concretas de produção imobiliária na cidade. Porém, ao estabelecer formas permitidas e proibidas, acaba por definir territórios dentro e fora da lei, ou seja, configura regiões de plena cidadania e regiões de cidadania limitada. (ROLNIK, 1999. p.13).

Os princípios do urbanismo moderno-funcionalista forjaram a legislação urbanística no Brasil ao longo do século XX, desconsiderando dinâmicas da cidade existente e lançando mão de padrões pré-concebidos, expressos por meio de índices urbanísticos e pela separação de usos como forma de garantir que cada parte da cidade cumprisse plenamente sua função definida a partir de um modelo teórico. Modelo que foi incapaz de garantir a pretensa ordem social e formal da cidade e, pelo contrário, gerou mais segregação (SANTOS, 2009).

Ao analisar as noções de ordem e irregularidade no espaço urbano, Silva (2006) ressalta que "a falência dos mecanismos de controle urbanístico é visível nas nossas cidades" (SILVA, 2006. p.90). A autora se refere justamente à ordem funcionalista que produziu normas

para uma cidade das elites e das classes médias [que] não atende às demandas das classes de baixa renda, e faz com que estas sejam atendidas pelo mercado imobiliário informal. O Estado não reconhece as práticas sociais destes grupos, e tenta impingir normas que não levam em conta a realidade urbana e suas contradições. (SILVA, 2006. p.99).

O Brasil teve avanços desde o processo de redemocratização nos anos 1980, cujos marcos legais e simbólicos principais são o capítulo da política urbana da Constituição Federal de 1988 e o Estatuto da Cidade. Ao serem aprovados, sinalizavam para possibilidades de construção de cidades mais inclusivas e, especialmente o Estatuto da Cidade, expunha, por meio das diretrizes para política urbana no Brasil (art. $2^{\circ}$ ), o diagnóstico de uma série de conflitos nas cidades brasileiras.

Apesar da sofisticação da legislação federal e do esforço para se elaborar novos instrumentos municipais de planejamento e gestão (planos diretores pós-Estatuto da Cidade) que pudessem contribuir para efetivação do direito à cidade, a renovação de instrumentos operacionais do planejamento urbano e, mais ainda, das práticas de gestão são extremamente tímidas. Os planos diretores pós-Estatuto da Cidade, de modo geral, não aproveitaram como poderiam o potencial dos instrumentos consagrados na lei federal. E os processos de elaboração dos planos não foram necessariamente acompanhados da revisão da legislação urbanística ordinária, o que muitas vezes resultou em incompatibilidades deixadas à interpretação dos licenciadores e em justificativas para não serem levados adiante.

A questão operacional, entretanto, não diz respeito apenas às normas em si, mas às práticas de gestão de modo amplo, que envolvem tradicionalmente atividades de planejamento, 
licenciamento e fiscalização. Conforme aponta Garcia, "as ações, diretrizes e políticas definidas no planejamento exigem uma conversão para o nível de praxis, demandando atos regularizados e rotinas, (...), que demandam pessoas, informações e processos de trabalho" (GARCIA, 2013. p.212). A integração entre essas atividades essenciais nem sempre ocorre efetivamente, como destaca o próprio Garcia:

Apesar do licenciamento ser prática comum nos Municípios (mesmo com toda a sua deficiência), sua relação com o planejamento nem sempre se dá de modo evidente. Em alguns casos as licenças são emitidas sem que preexistam dispositivos de orientação e disciplinamento em relação aos impactos na paisagem, no trânsito, na vizinhança, no ambiente, na economia etc. definidos a partir de um desejo coletivo de ordem. Noutros casos, é o próprio processo de planejamento que ignora o licenciamento enquanto instrumento efetivo de controle do uso e ocupação do solo, indispensável para a implementação do próprio plano (...) (GARCIA, 2013. p.214).

Observa-se, ainda, que, em geral, as atividades de licenciamento e fiscalização, são desprestigiadas nas administrações municipais brasileiras. Tanto do ponto de vista do status profissional dos que a exercem, como da própria alocação de recursos para o seu bom funcionamento frente à dinâmica urbana e frente a uma legislação urbanística e ambiental normalmente pesada. São atividades tidas como menores na gestão urbana, embora lidem com a construção da cidade no dia a dia, lá na ponta, na relação direta com o cidadão. As atividades de planejamento, tradicionalmente tidas como mais nobres, continuam, com frequência, a serem desenvolvidas nos gabinetes, revendo permanentemente as normas vigentes, sem terem ou sem considerarem o feedback do licenciamento e, não raramente, descoladas do mundo real.

A terceira dimensão da negligência urbanística na abordagem proposta é projetual e diz respeito à própria natureza dos projetos urbanos, os tipos de intervenções, como essas dialogam ou interferem na dinâmica urbana e as concepções urbanísticas adotadas.

A prática de projetos urbanos revela contradições entre um arcabouço teórico que busca situá-la como alternativa aos pressupostos do urbanismo funcionalista e para enfrentamento das problemáticas próprias da cidade contemporânea e suas formas de apropriação por agentes econômicos e políticos. De acordo com Merlin e Choay (2010), tais contradições vão desde aspectos conceituais mais gerais como, por exemplo, o entendimento do projeto urbano como parte da lógica da associação entre gestão urbana e gestão empresarial - que põe em conflito a necessidade do tempo longo da cidade e as expectativas de resultados em tempo curto das empresas ${ }^{4}$-, a questões mais pragmáticas como a utilização eleitoral dos projetos urbanos no jogo político. Do ponto de vista arquitetônico urbanístico, essas contradições podem se traduzir em conteúdos esvaziados dos projetos urbanos, reduzindoos, muitas vezes, à produção de formas e imagens para servir às estratégias de marketing urbano e favorecer interesses privados de empreendedores e grupos econômicos - ou "exigências do mercado" - em detrimento dos interesses coletivos.

Farias Filho (2007) ressalta que noção e prática de projetos urbanos encerram uma polarização: "onde uns vêem um instrumento de manipulação da cidade articulado pelas forças econômicas, outros observam um modus operandi capaz de contribuir para a melhoria e democratização do espaço urbano" (FARIAS FILHO, 2007. p.1). Entre esses dois polos, se pode pensar a prática de projetos urbanos do Rio de Janeiro nas últimas três

$4 \quad$ De acordo com os autores, “a identificação da gestão da cidade com a gestão de empresa traz o problema de compatibilidade conceitual: como conciliar os elementos de regulação e de duração com os elementos da vida das empresas que são frenquentemente de curto prazo? De fato, o projeto urbano, o projeto aplicado à cidade, toca o interesse público, enquanto o projeto de empresa refere-se ao interesse privado" (MERLIN E CHOAY, 2010, tradução nossa). 
décadas. Numa cidade marcada por desigualdades, a questão de fundo é se os projetos urbanos têm servido à reconstituição da urbanidade e à integração socioespacial ou, opostamente, ao aprofundamento da segregação urbana. A resposta não é tão simples e é, de certo modo, ambígua, pois é possível reconhecer experiências que opera(ra)m nos dois sentidos.

No entanto, ao se lançar o olhar para a prática de projetos urbanos ao longo do tempo, é possível perceber como a ação projetual vai se tornando, ao menos no contexto carioca, cada vez mais negligente em relação a essa perspectiva da democratização do espaço urbano, da concepção de um projeto de cidade mais inclusiva. Nesse sentido, as ações de preparação da cidade do Rio de Janeiro para os grandes eventos esportivos internacionais e a operação urbana "Porto Maravilha" expressam mais claramente a ideia de negligência urbanística projetual. No seu conjunto, são concentradoras de investimentos em áreas cuja expectativa de apropriação de valorizações fundiárias pelo mercado imobiliário é gigantesca, reforçam tendências de segregação no espaço urbano, reproduzem modelos urbanísticos e arquitetônicos exógenos e desprezam a participação social. São, na verdade, grandes operações imobiliárias e financeiras ou grandes obras de infraestrutura cujos "projetos urbanos" vêm "a reboque".

\section{Dispersão e Informalidade Urbanas no Rio de Janeiro}

No Rio de Janeiro, pelo menos dois fenômenos se mostram essenciais para compreensão do desenvolvimento urbano das três últimas décadas: a dispersão urbana e a informalidade urbana. Esses são aqui ressaltados como expressão física e territorial do quadro de negligência urbanística no Rio de Janeiro. Certamente, não são fenômenos novos, uma vez que acompanham o processo de urbanização da cidade em todo o século XX. Porém, o modo como se configuram nas últimas décadas é diferente.

Nesse período recente, o crescimento populacional acelerado não pode mais explicálos, pois a população carioca tem crescido pouco nas últimas décadas. Apesar do baixo crescimento populacional, constrói-se muito na cidade, sobretudo nos bairros com menos infraestrutura, pressionando a expansão da urbanização e provocando significativos movimentos internos da população. Os efeitos sobre as áreas de urbanização mais antigas e melhor infraestruturadas variam entre a hiper-valorização dos bairros mais nobres e a deterioração de bairros dos subúrbios, reforçando desigualdades territoriais.

Os dados mais gerais de população e domicílios indicam dois movimentos em curso na cidade do Rio de Janeiro: um de manutenção do vetor de expansão para a zona oeste na última década, com maior peso na ocupação da $\mathrm{AP} 4^{5}$, e outro, menos intenso, de retorno aos bairros mais centrais da AP2 e AP1. Se num primeiro momento, o retorno aos bairros centrais parece ser algo positivo, não há indícios claros de que tenha surgido qualquer reversão de lógica do processo de urbanização mais geral. Os novos produtos imobiliários ofertados na zona sul e área central pelo mercado dirigido, sobretudo, a famílias de média e alta renda, a atuação muito restrita dos programas habitacionais na área central e a incrível alta dos preços dos imóveis desde 2008 são indícios de radicalização do processo de segregação da cidade, que tradicionalmente tem empurrado para as favelas, para a zona oeste e para as periferias metropolitanas a população mais pobre.

$5 \quad$ O Sistema de Planejamento do Rio de Janeiro subdivide a cidade em cinco Áreas de Planejamento (AP). A AP1 corresponde a área central; a AP2 abrange a zona sul e parte da zona norte; a AP3 engloba os bairros dos subúrbios e as AP4 e AP5 formam a zona oeste da cidade.

Cabe destacar que a partir de 2009, o vetor de expansão da cidade na parte norte da zona oeste foi impulsionado pela ação do Programa Minha Casa Minha Vida. No âmbito, do Programa, cerca de $75 \%$ das unidades licenciadas estão localizadas na oeste (AP4 e AP5). 
Dispersão da urbanização e crescimento da informalidade urbana ocorrem concomitantemente, se alimentam e são estruturantes na dinâmica urbana carioca. De um lado, pode se dizer, a dispersão urbana é fomentada diretamente pela ação pública sobre o espaço urbano por meio de obras públicas. A informalidade, por sua vez, é, em grande parte, reflexo da omissão que historicamente caracterizou a postura do Estado em relação à questão habitacional, resultando no gigantesco passivo urbanístico-ambiental atual.

Mas esses dois fenômenos estão relacionados também com opções do próprio planejamento, como demonstram o "Plano Piloto para urbanização da baixada compreendida entre a Barra da Tijuca, o Pontal de Sernambetiba e Jacarepaguá" (1969), ou mais simplesmente "Plano Lucio Costa", e o Decreto 322/1976, que trata do zoneamento e normas de edificação no município do Rio de Janeiro. Representantes legítimas do planejamento urbano tradicional, totalizante e totalitário, tanto na forma mais poética do Plano Lucio Costa, quanto na forma mais burocrática e tecnocrática do Decreto 322/76, as duas "decisões urbanísticas" continuam vigorando, quatro décadas depois, apesar de suas sucessivas alterações, moldando a cidade que se constrói dia a dia, formal ou informalmente, ao longo do tempo. Elas ilustram bem que a base operacional do urbanismo, representada pela legislação urbanística, tem papel preponderante na configuração da cidade, sendo possível até mesmo afirmar que dispersão e informalidade são também "planejadas".

Como destacado acima, mesmo tendo crescimento populacional a taxas baixas e estáveis, tal como indicam os dados dos últimos Censos Demográficos do IBGE, a malha urbana do Rio de Janeiro continua a expandir muito. E essa é uma das questões de fundo sobre sua dinâmica urbana recente e sobre o papel a ser desempenhado pelo urbanismo nesse contexto. Andrade (2009) destaca que a cidade vive atualmente um período de retração, mas que, paradoxalmente, "o Rio de Janeiro, além de se retrair, se muda". (ANDRADE, 2009. p.5). E se muda num processo de urbanização que avança, com descontinuidades, e tem a ocupação intensificada sobre as áreas com menos ou nenhuma infraestrutura, deixando um rastro de subaproveitamento em bairros antigos.

Os dados demográficos demonstram o impressionante movimento da cidade em direção à zona oeste e o gradativo aumento da população residente em favelas, tanto em termos absolutos como relativos. A excessiva expansão da cidade resulta em problemas urbanos cada vez mais complexos, particularmente em relação às infraestruturas e à mobilidade. E a informalidade urbana também aumenta. De acordo com os Censos do IBGE, em 1980 a população residente em favela era 14,09\% da total; em 1991 era 16,10\%, em 2000 era de $18,65 \%$ e em 2010 era de $22,04 \%$.

O fenômeno da informalidade urbana no Rio de Janeiro não se restringe às favelas, embora essa seja a sua face mais visível e em relação à qual os dados disponíveis permitem o dimensionamento mais confiável. Os loteamentos clandestinos e irregulares constituem outro padrão de assentamento popular informal também bastante expressivo. Mas o fenômeno da informalidade é ainda mais amplo e apesar de sua quase indissociabilidade em relação à pobreza, não se trata de "privilégio" dos pobres ${ }^{6}$. A associação direta entre pobreza e informalidade urbana, na forma de causa e consequência, encobre outros elementos associados ao fenômeno e, de certo modo, o naturaliza e alimenta preconceitos. Fernandes (2011) assinala que "embora a maioria dos habitantes de assentamentos informais seja, de fato, pobres, pobreza não é a única causa do loteamento informal de terras" (FERNANDES, 2011. p. 14). Tomando como referência o exemplo do Rio de Janeiro, o autor confirma seu argumento lembrando que na cidade "as taxas de crescimento informal têm sido superiores às taxas de crescimento da população urbana e da pobreza" (FERNANDES, 2011. p. 14). Apesar

6 Veríssimo apud Fernandes e Affonsin, 2003 (Curso Regularização Urbanística e Fundiária de Assentamentos Informais de Baixa Renda, IBAM, 2007). 
dos limites dos dados disponíveis do licenciamento urbanístico e das possiblidades de comparação desses com dados censitários, é possível estimar (BARANDIER, 2015, p.52-59) que apenas cerca de um terço da produção de unidades residenciais da cidade do Rio de Janeiro, no período entre 2000 e 2010, atendeu a todos os requisitos do processo formal de licenciamento. Estima-se que em torno de $65 \%$ das unidades residenciais acrescidas ao estoque eram irregulares, sendo $35 \%$ em favelas e $30 \%$ não localizadas em favelas. Ainda que se possa admitir que parte dessas possam representar irregularidades apenas documentais, os números estimados sugerem a existência de um fosso entre o planejamento urbano e a realidade da cidade. Assim, parte significativa da cidade ainda se constrói à margem da legislação urbanística e do sistema de controle urbano, em grande medida ainda baseado no modelo tradicional de planejamento - modernista, funcionalista, tecnocrático, elitista etc. Um tipo de urbanismo que segundo Maricato "não tem comprometimento com a realidade concreta, mas com uma ordem que diz respeito a uma parte da cidade, apenas" (MARICATO, 2002. p. 122).

O quadro aqui apresentado talvez não apresente nenhuma interpretação inovadora sobre fenômenos que já caracterizavam o desenvolvimento urbano do Rio de Janeiro na década anterior. Mas é exatamente por isso que se torna relevante, pois expõe a continuidade de situações e processos que já eram conhecidos, apesar de discursos e práticas que seriam transformadoras da cidade.

A priorização dos projetos urbanos na gestão da cidade desassociada do processo de planejamento urbano ordinário, reduzido a revisões pontuais das normas e aplicação parcial e discricionária delas no licenciamento, aparentemente, contribuiu significativamente para um quadro de inércia frente a lógicas do desenvolvimento urbano do Rio de Janeiro. Quando, nos anos 1990, a palavra de ordem era a de que "era preciso agir" - diante de uma interpretação de que a cidade estava abandonada etc. - essa desvinculação mostrou alguma eficácia no curto prazo. A execução de uma série de obras de qualificação do espaço público realizadas simultaneamente teve impacto significativo num primeiro momento em que a cidade parecia reconstruir sua imagem. No longo prazo, porém, nem se constituiu uma cultura de projetos urbanos na cidade, nem se reformulou as bases e práticas do urbanismo operacional, nem se reverteu processos urbanos que tendem a produzir uma cidade mais desigual.

\section{Três Gerações de Projetos Urbanos no Rio de Janeiro}

Expressão de uma nova perspectiva de conceber e orientar a estruturação do espaço urbano ou nova maneira de organizar a ação de agentes econômicos na cidade, a prática de projetos urbanos é reconhecida como forma de intervenção privilegiada do urbanismo contemporâneo nos mais diversos países. É razoavelmente consensual na literatura sobre o tema, que o projeto urbano na sua versão atual se desenvolve, ao menos inicialmente, a partir da crítica ao urbanismo modernista/funcionalista e do contexto de transformações econômicas e políticas do final do século XX.

“O termo 'projeto urbano' apareceu verdadeiramente, na sua versão conjuntural, no momento em que, ao final do grande período de expansão dos anos 60, se experimentava dissociar a planificação excessivamente sistemática e mecânica do espaço e descobrir novas racionalidades, menos desvinculadas dos homens, mais próximas de suas aspirações, e provavelmente mais complexas" (RONCAYOLO, 2000. p.25, tradução nossa).

Cerca de quatro décadas depois, as abordagens sobre o projeto urbano e as interpretações sobre o seu papel são múltiplas e mesmo contraditórias e conflitantes. Tudo coerente com o tempo de incertezas em que vivemos, da modernidade líquida descrita por Bauman 
$(2001 ; 2007)$. Ainda mais para um termo que ganha expressão na Europa - sendo introduzido somente mais tarde no Brasil - justamente na época em que se revelava mais claramente a crise da modernidade: o momento do "aparecimento da incerteza lá onde tudo parecia seguro, regrado, regulado e, portanto, predicável” (MORIN, 2012. pp. 19-20).

A compreensão do debate sobre projeto urbano no Brasil passa pelo entendimento do contexto bastante particular da virada dos anos 1980 para os anos 1990 no país. No processo de redemocratização da década de 1980, movimentos sociais, academia, ONGs, associações profissionais, se organizaram em torno da luta pela reforma urbana, do direito à cidade e do direito à moradia. A articulação entre lideranças populares, intelectuais e profissionais permitiu a formação de uma consciência crítica sobre a realidade urbana brasileira e a organização do Movimento Nacional de Luta pela Reforma Urbana. A partir da emenda popular apresentada pelo movimento, a Constituição Federal de 1988 incorporou o que seriam as bases para reforma urbana: a afirmação do princípio da função social da cidade e da propriedade urbana; a utilização compulsória de imóveis vazios ou subutilizados em áreas urbanas bem infraestruturadas; a regularização fundiária de interesse social. A transição democrática, o novo marco constitucional, a chegada de partidos de esquerda ao poder executivo de importantes cidades, notadamente São Paulo, indicavam, no final dos anos 1980, possibilidades reais de mudanças de prioridades na política urbana brasileira.

No entanto, a ascensão dos ideais neoliberais nos anos 1990 foi acompanhada de outra agenda para as cidades, se sobrepondo àquela preconizada pelo movimento da reforma urbana. A polarização político-ideológica que se acirraria ao longo da década se traduziu, no campo da política urbana, na oposição entre plano e projeto, entre planejamento urbano e planejamento estratégico, entre participação social e parcerias público-privada, entre regulação urbana e flexibilização da legislação urbanística...

Claramente, se opunham dois modelos de planificação. Um que buscava a afirmação dos direitos sociais, o fortalecimento da regulação urbana pelo Estado e a intervenção no mercado fundiário por meio da revisão da legislação urbanística e a intensificação do controle social na implementação da política urbana. Outro que reivindicava normas urbanísticas flexíveis, a regulação urbana pelo mercado e, nesse caso sim, a implementação de projetos urbanos como estratégia para atração de investidores, turismo e conferir à cidade a imagem de modernidade e dinamismo.

Assim, observa-se que a noção de projeto urbano entra no contexto brasileiro atrelada à onda neoliberal dos anos 1990, sendo de fato difícil de desassociar uma coisa e outra. Por outro lado, registra-se que no ideário da reforma urbana, o projeto - condição essencial para produção do espaço urbano e da arquitetura de qualidade - não era tido como instrumento de promoção de justiça social na cidade.

No contexto brasileiro, a cidade do Rio de Janeiro pode ser considerada como um laboratório de experiências em projetos urbanos em razão das diversas propostas, de diferentes naturezas, que têm sido anunciadas nas últimas décadas, ainda que nem sempre efetivamente implementadas. Tomando-se como referência o marco da redemocratização, a prática de projetos urbanos no Rio de Janeiro é marcada, de acordo com a leitura aqui proposta, por três momentos principais.

O primeiro, nos anos 1980, é o de experiências precursoras, quando, no ambiente de abertura democrática, se buscava formas de participação social e a proposição de novos temas para a agenda urbana. É o momento de projetos como o inovador Corredor Cultural, o Projeto SAGAS entre outros com grande ênfase na preservação de conjuntos de interesse histórico e cultural. É também o momento de programas em favelas como - Cada Família um Lote e Projeto Mutirão, que expressavam novas abordagens para a questão das favelas, na perspectiva da regularização e da participação comunitária. 
O momento seguinte, mais claramente demarcado entre 1993 e 2000, é de inflexão, quando se estrutura um novo discurso sobre a cidade no qual o projeto urbano, como estratégia de intervenção pública, assume lugar central. Abrange as administrações César Maia e Luiz Paulo Conde, quando programas como Rio Cidade e Favela Bairro ganharam grande destaque por contratarem, por meio de concursos, equipes multidisciplinares coordenadas por arquitetos para elaboração de projetos e por realizarem projetos e obras em diversos bairros ou favelas simultaneamente, o que conferiu à ação sobre o espaço urbano uma nova dimensão. Nesse mesmo período, foram propostos diversos projetos para a área central que propunham o redesenho de grandes áreas localizadas em bairros vizinhos ao Centro, diferentemente do Corredor Cultural cujo foco era a preservação de conjuntos urbanos no próprio Centro.

E o terceiro momento se inicia no começo dos anos 2000, quando surge uma série de intervenções concebidas em torno de grandes projetos arquitetônicos, muitos deles de forte apelo midiático e, eventualmente, assinados por estrelas da arquitetura internacional. Como produtos dessa mesma geração de projetos urbanos, figuram também os inúmeros projetos e obras associados direta ou indiretamente à realização dos grandes eventos esportivos na cidade.

Essa terceira geração de projetos urbanos, no nosso ver, se descola de qualquer discurso urbanístico mais estruturado, diferentemente do que se passava nos anos 1990, e assume um caráter genérico, em que se almeja a construção de uma imagem de cidade internacional para o Rio de Janeiro. A realização dos eventos esportivos e o lançamento de projetos assinados por estrelas da arquitetura mundial fazem parte dessa estratégia. O "legado" dos eventos esportivos e a renovação da área portuária seriam as forças transformadoras da cidade.

Para compreensão das distinções entre as três gerações de projetos urbanos aqui identificadas, destacamos três aspectos que parecem essenciais: a forma urbana, os objetos de intervenção e os agentes formuladores dos projetos.

Nos projetos dos anos 1980, a forma urbana é compreendida como processo. Ou seja, o projeto parte do reconhecimento do existente, que não é apenas o espaço físico, mas também suas formas de apropriação pelos grupos sociais. O resultado formal da intervenção se definirá ao longo do tempo e em função da participação e adesão dos usuários ao projeto. Nos anos 1990, a forma urbana é desenhada. Tem também como princípio o respeito ao existente, mas agora tem mais peso a visão que confere certa autonomia à forma urbana. É valorizada a capacidade do projeto urbano de reordenar os espaços públicos e reconfigurar o ambiente construído a partir do desenho urbano. A partir dos anos 2000, a forma urbana é tratada como imagem. A cidade existente é o pano de fundo e as intervenções urbanas produzem novos símbolos, se expressam por grandes obras que sugerem uma cidade pretensamente dinâmica.

Quanto aos objetos de intervenção dos projetos urbanos também há mudanças significativas, mas nesse caso é necessário distinguir as diferentes temáticas abordadas. Ainda que nos anos 1990, o espaço público seja o objeto principal do projeto urbano, as abordagens sobre as duas temáticas mais recorrentes - área central e favelas - permitem pontuar as características de cada geração.

Em relação à área central, a primeira geração de projetos tem como objeto o próprio bairro Centro. De um lado, trata da proteção legal de alguns conjuntos urbanos. Por outro envolve inúmeras pequenas intervenções nos espaços públicos (ruas, praças e largos). Na segunda geração de projetos urbanos, embora tenham continuidade as ações do período anterior, o espaço pericentral passa a ser objeto de projetos urbanos. Aí não são apenas os espaços públicos, mas áreas deterioradas e/ou subaproveitadas para as quais são propostos projetos com o intuito de introduzir novas dinâmicas na área central. E a terceira geração 
de projetos tem como objeto prioritário a área portuária. Trata-se de uma grande área vista como vazio (apesar dos usos e atividades ali existentes) a ser ocupado.

Do mesmo modo, a temática das favelas não envolve um único objeto de intervenção. Nos anos 1980, o objeto das ações em favelas não é bem delimitado. As ações são pulverizadas, às vezes muito pontuais numa ou noutra favela. Nos anos 1990, a problemática das favelas é bem mais conhecida, até mesmo pelas experiências da década anterior, o que favoreceu intervenções mais articuladas. Mas é importante destacar que as ações de urbanização passam a abranger, ao menos potencialmente, o conjunto de favelas da cidade e cada projeto tem como objeto uma favela integralmente. Ou seja, o objeto da intervenção é a favela como um todo e os programas municipais abrangem todos os tipos de favela. Nos projetos da última geração, há o interesse específico sobre as favelas mais emblemáticas da cidade. É nessas favelas que são construídas as grandes obras - em especial os teleféricos, planos inclinados, elevadores - cujos impactos não se restringem às próprias favelas, mas extrapolam para a cidade e redefinem a paisagem urbana.

A outra diferença marcante e, pode se dizer, definidora da natureza dos projetos urbanos de cada geração diz respeito aos agentes formuladores dos projetos. Nos anos 1980 , os protagonistas são os técnicos municipais. Ao mesmo tempo que buscavam novas práticas do urbanismo, favorecidas pelo ambiente de redemocratização, eram agentes da máquina pública, o que talvez explique a dupla característica dos projetos de serem ações no espaço urbano ao longo do tempo e de se traduzirem também em propostas normativas. Nos anos 1990, o arquiteto profissional liberal e de escritórios de arquitetura assume o protagonismo. Trata-se de um novo agente na formulação de propostas urbanísticas para a cidade, pois não são mais apenas uma categoria profissional que discute a cidade, mas são responsáveis pela coordenação de projetos. E a resposta desse tipo de profissional é por meio do desenho urbano, de projetos que devem orientar a execução das obras. A partir dos anos 2000, surgem na cena carioca projetos elaborados por estrelas da arquitetura internacional, que contribuem decisivamente para a valorização de objetos arquitetônicos nos projetos urbanos e a dimensão icônica da arquitetura. Paralelamente, as grandes empreiteiras e suas subsidiárias do ramo de construção civil é que passam a ter papel privilegiado na definição e mesmo concepção dos projetos urbanos. Não é à toa que grandes obras voltam à ordem do dia, associadas à liberação de índices urbanísticos e impulsionadas pelo novo sopro desenvolvimentista vivido pelo país.

As três gerações de projetos urbanos têm em comum o fato de não terem interferido nos dois grandes processos urbanos estruturantes da cidade nas ultimas décadas descritos anteriormente: a dispersão urbana, com movimento da cidade na direção oeste do território, e o crescimento da informalidade urbana.

A primeira geração de projetos urbanos, pode se dizer, se beneficiou e se viabilizou em alguma medida justamente em razão desses processos. A consolidação da região da Barra da Tijuca como vetor de expansão da cidade abria espaço para as ações preservacionistas no Centro, uma vez que era para aquela região que se voltava o mercado imobiliário, inclusive com perspectivas de lá se instalar o novo Centro Metropolitano. A expansão da informalidade, se não é possível dizer que fosse propriamente fomentada, é forçoso observar que resultava em novas áreas para o exercício do clientelismo político, no momento em que o Estado se posicionava contrariamente às políticas de remoção de favelas do passado.

A segunda geração de projetos urbanos ao mesmo tempo que se estrutura sob o slogan do "urbanismo de volta às ruas" e da valorização do espaço público, que, de certo modo, está relacionado com o resgate da cidade tradicional, não intervém nesses processos maiores, já muito claros na década de 1990. Mas a não intervenção nas lógicas do mercado era também postura coerente com as opções políticas do período, que pregavam menor regulação dos 
mercados pelo poder público. A região da Barra da Tijuca viu sua ocupação se intensificar, continuando a ser beneficiada por investimentos públicos, inclusive grandes obras viárias, o que se mostra contraditório com o discurso. E mesmo o amplo programa de urbanização de favelas, apesar de sua relevância, não conseguiu conter a informalidade crescente, pois não incidia sobre as causas.

E a terceira geração de projetos integra uma estratégia política que não apenas não interfere nos fenômenos de dispersão e informalidade, como tende a contribuir para reforçá-los. A concentração de investimentos na região da Barra da Tijuca em nome da realização dos grandes eventos esportivos internacionais e a convergência da nova infraestrutura de transportes (BRTs e expansão do metrô) para essa região demonstram a opção pela criação de novas condições para intensificar sua ocupação. Ao mesmo tempo, a produção habitacional, no momento em que finalmente houve política de subsídio no país, direcionou a população de baixa renda para o limite da urbanização com nova edição da política de construção de grandes conjuntos, longe do Centro e longe das áreas destinadas aos mercados de média e alta renda. A renovação da área portuária, embora anunciada como prioridade, diante das renovadas tendências de dispersão urbana, se mostra mais como projeto de caráter essencialmente especulativo e voltado para a viabilização de algumas grandes obras do que como parte fundamental de um novo projeto de cidade.

\section{Considerações Finais}

Quando se levantou, para reflexão e discussão, o tema da forma negligente como vêm sendo construídas as cidades, com a atenção voltada especialmente para as brasileiras, pensava-se sobretudo, que elas poderiam, e podem, ser diferentes. Menos desiguais e mais acolhedoras. Nesse sentido, a noção de negligência urbanística tal como foi abordada, antes de mais nada, se contrapõe à naturalização dos processos urbanos, algo que perpassa e, muitas vezes, justifica discursos, práticas e também inações em relação às cidades.

A hipótese principal que norteou a tese sobre qual se baseou este artigo era a de que se constituiu, ao longo do tempo, um quadro de negligência urbanística no contexto carioca de tal ordem, que compreendê-lo seria condição indispensável para o entendimento do modelo de desenvolvimento urbano e o significado das tendências atuais do Rio de Janeiro. A conjugação entre displicência no controle do uso e ocupação do solo, concentração de investimentos públicos em áreas priorizadas pelo mercado imobiliário e realização de intervenções urbanas de grande apelo midiático opera na contramão de uma agenda para construção de uma cidade mais inclusiva e ambientalmente mais equilibrada. Pelo contrário, reforçam-se tendências de segregação socioespacial e de reprodução de padrões insustentáveis de urbanização na cidade.

Embora os estudos aqui empreendidos tenham se debruçado sobre a cidade do Rio de Janeiro, entende-se que o conceito de negligência urbanística pode ter caráter universal. É válido para diferentes realidades, pois se apoia, segundo a fundamentação teórica adotada, na ideia de responsabilidade. Num sentido mais amplo, quando se enfatiza a responsabilidade, se reafirma que cabe às sociedades contemporâneas enfrentar de modo efetivo os problemas próprios do fenômeno da urbanização, que, em diferentes contextos e de diferentes formas, se apresentam na precariedade das cidades, ou de partes delas, nas desigualdades socioespaciais das áreas urbanas, nas barreiras ao pleno exercício do direito à cidade.

No exercício de constituir a associação entre negligência e processos de urbanização como questão teórica, desenvolveu-se a noção de negligência urbanística em três dimensões: estrutural, operacional e projetual. Tais dimensões emergem dos estudos desenvolvidos sobre o Rio de Janeiro e, ao serem amadurecidas conceitualmente, também alimentaram o próprio exercício analítico empreendido. 
Mesmo sem a pretensão de classificar os fenômenos e processos estudados numa ou noutra dimensão especificamente, até porque essas se sobrepõem, foi possível constatar que elas estão presentes na realidade carioca. Muito claramente, no fomento à expansão urbana desnecessária e que produz impactos negativos na cidade de diferentes ordens; na incapacidade de se fazer frente à informalidade urbana crescente; nas resistências a mudanças reais na concepção de regulação da produção urbana; na deslegitimação do plano como instrumento de gestão e, mais ainda, do próprio processo de planejamento; nos projetos que reproduzem localmente experiências tidas como de sucesso em outras cidades, mas inadequadas ao nosso contexto; na ânsia por se construir novos ícones arquitetônicos - que criam imagens, mas, possivelmente, destroem identidades.

A valorização do projeto como instrumento de intervenção na cidade relativamente autônomo, no entanto, trouxe algumas novidades importantes que merecem registro. Entre elas, a preocupação com o espaço público como elemento estruturador da urbanidade, apesar do enviesado discurso de ordem dominante. Não obstante, a partir da opção de privilegiar a ação, a prática de projetos urbanos no Rio de Janeiro se desenvolve, pode-se dizer, segundo uma lógica própria, desarticulada do "urbanismo cotidiano" que constrói a cidade dia a dia dentro e fora da norma. O foco de renovação da gestão recai sobre intervenções no espaço urbano, na perspectiva de construir uma nova imagem da cidade. E nesse contexto, se advoga a flexibilização das normas urbanísticas ao invés da renovação, em outras bases conceituais, do aparato normativo e instrumental de gestão urbana ordinária de tradição elitista, tecnocrática e burocrática. Passa-se, então, a privilegiar "oportunidades", normalmente de negócios, em relação à discussão e definição de prioridades. As ações exemplares ao processo de planejamento e à construção cotidiana da cidade.

Assim, é possível afirmar que apesar de experiências inovadoras e até mesmo exitosas que eventualmente possam ser identificadas na prática de projetos urbanos no Rio de Janeiro desde os anos 1980, a maneira como se opera a construção da cidade continua sendo, de modo geral, determinada muito mais pela execução de obras públicas setoriais (intervenções viárias, conjuntos habitacionais, equipamentos urbanos etc), pela aplicação de legislação urbanística anacrônica, pelas lógicas do mercado imobiliário e pelo puro "laisser-faire". Paralelamente, tal como se configurou no Rio de Janeiro, sobretudo no período mais recente, impulsionado por uma nova onda desenvolvimentista e pela euforia com a realização de grandes eventos esportivos internacionais, o projeto urbano acaba por se constituir como instrumento de um urbanismo de exceção, que incide seletivamente no território e reforça dinâmicas de segregação no espaço urbano.

O conceito de negligência urbanística instiga o questionamento sobre os arranjos políticos e os fundamentos técnicos que se entrelaçam na gestão urbana e orientam sua condução, seja na cidade do Rio de Janeiro, seja em outras realidades. A partir dele, nas três dimensões aqui propostas - estrutural, operacional e projetual - acreditamos que podem se abrir novas perspectivas para se pensar o modo como as cidades são construídas e os desafios relacionados ao fenômeno urbano no século XXI. 


\section{Referências bibliográficas}

ABREU, Mauricio de A. Evolução urbana do Rio de Janeiro. Rio de Janeiro: IPLANRIO/ Jorge Zahar, 1987.

AGRAR / LE COCQ, Sonia (Coord.). Projeto Caracterização da Irregularidade Urbanística Edilícia e Fundiária: Subsídios para a Regularização na Cidade do Rio de Janeiro. Rio de Janeiro, Agrar Consultoria e Estudos Técnicos, 2002. (Relatório)

ANDRADE, Carlos Fernando. Rio de Janeiro: urbanismo em tempos de retração. 2009. 242 f. Tese (Doutorado em Urbanismo) - Programa de Pós-graduação em Urbanismo, Universidade Federal do Rio de Janeiro.

ARANTES, Otília; VAINER, Carlos; MARICATO, Ermínia. A cidade do pensamento único: Desmanchando consensos. Petrópolis, Editora Vozes, 2000.

ASCHER, François. Les nouveaux principes de l'urbanisme. Edition de poche. L'Aube, 2004.

BARANDIER, Henrique. Projetos Urbanos para área central do Rio de Janeiro (19932000). 2003. 145f. Dissertação (Mestrado em Urbanismo). Programa de Pós-graduação em Urbanismo, Universidade Federal do Rio de Janeiro.

BARANDIER, Henrique. Negligência Urbanística e Projeto Urbano na Cidade do Rio de Janeiro. 2015. 237f. Tese (Doutorado em Urbanismo). Programa de Pós-graduação em Urbanismo, Universidade Federal do Rio de Janeiro.

BASSUL, José Roberto. O Estatuto da Cidade dez anos depois. In: Estatuto da Cidade 10 anos: avançar no planejamento e na gestão urbana. Brasília: Senado Federal, gabinete do Senador Inácio Arruda, 2011. pp.9-16.

BAUMAN, Zygmunt. Confiança e medo na cidade. Rio de Janeiro, Zahar, 2009.

BOURDIN, Alain. L'urbanisme d'après crise. L'Aube, 2014.

COMPANS, Rose. Empreendedorismo urbano: entre o discurso e a prática. São Paulo, Editora UNESP, 2005.

GARCIA. Romay C. Planos diretores: relações com o licenciamento e a fiscalização. In: BARANDIER, $\mathrm{H}$. et al. (orgs). Planejamento e controle ambiental-urbano e a eficiência energética (Guia Técnico PROCEL EDIFICA). Rio de Janeiro: IBAM/DUMA; ELETROBRÁS/ PROCEL, 2013. pp.209-218.

FARIAS FILHO, José A. Projeto urbano: urbanismo de mercado ou fantasmagoria da cidade contemporânea? In: XII Encontro Nacional da Associação Nacional de Pósgradução e Pesquisa em Planejamento Urbano e Regional, 2007, Belém/PA. Anais... 2007. 19p.

FERNANDES, Edésio. Estatuto da Cidade, mais de 10 anos depois: razão de descrença ou razão de otimismo? Revista UFMG, Belo Horizonte, v.20, no 1, pp - 212-233, 2013.

HARVEY, David. Cidades rebeldes: do direito à cidade à revolução urbana - tradução Jeferson Camargo. São Paulo: Martins Fontes - selo Martins, 2014.

INGALLINA, Patrizia. Le projet urbain. Paris: Ed. Presses Universitaires de France, 2001.

MARICATO, Ermínia. As idéias fora do lugar e o lugar fora das idéias - Planejamento urbano no Brasil. In: ARANTES, O.; VAINER, C.; MARICATO, E. A Cidade do Pensamento Único: desmanchando consensos. Petrópolis: Vozes, 2000. pp. 121-192. 
MARICATO, Erminia. O impasse da política urbana no Brasil. Petrópolis, Editora Vozes, 2011.

MERLIN, Pierre; CHOAY, Françoise. Dictionnaire de l'urbanisme et de l'aménagement. Troisiéme Édition (Revue et Augmentée). Quadriage/PUF, 2010.

MORIN, Edgar. Para onde vai o mundo? 3a Edição. Petrópolis, Editora Vozes, 2012.

PINHEIRO MACHADO, Denise. Projetos urbanos, discursos e práticas (Relatório Parcial de Pesquisa). PROURB/UFRJ; CNPq. 2003.

PINHEIRO MACHADO, Denise. Projetos urbanos e cidades: desafios da metrópole contemporânea (Projeto de Pesquisa). PROURB/UFRJ; CNPq. 2010.

REZENDE, Vera F. A Evolução dos instrumentos de controle do espaço urbano na cidade do Rio de janeiro.. É possível planejar o futuro através da legislação? In: IV Seminário de História do Cidade do Rio de Janeiro, Rio de Janeiro, 1996, pp. 888-898.

RIBEIRO, Luiz César; SANTOS JUNIOR, Orlando. Desafios da questão urbana na perspectiva do direito à cidade. In: FERREIRA, R.; BIASOTTO, R. (orgs). Políticas Públicas e Direito à Cidade: Política Habitacional e o Direito à Moradia Digna (Programa Interdisciplinar de Formação de Agentes Sociais e Conselheiros Municipais). Rio de Janeiro: Letra Capital, 2012. pp.13-18.

ROLNIK, Raquel. A cidade e a lei: legislação, política urbana e territórios na cidade de

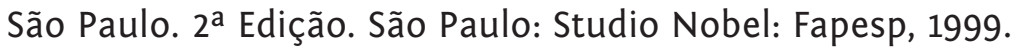

RONCAYOLO, Marcel. Mémoires, représentations, pratiques - réflexions autour du projet urbain. In: HAYOT, A. SAUVAGE, A. Le projet urbain: enjeux, expérimentations et professions. Éditions de La Villette (Études et Recherches), 2000. pp.25-31.

SANTOS, Carlos N. F. Está na hora de ver as cidades como são de verdade. BIB, Rio de Janeiro, nº 21, pp.599-63, 1986.

SANTOS, Carlos N. F. A cidade, os comportamentos e as leis. Revista de Administração Municipal - MUNICÍPIOS - IBAM. No271, pp.3-7, 2009. (Publicado originalmente na Revista de Administração Municipal nº 186, janeiro e março de 1988).

SANTOS JUNIOR, Orlando; MONTANDON, Daniel. Os planos diretores municipais pósEstatuto da Cidade: balanço crítico e perspectivas. Rio de Janeiro: Letra Capital, 2011.

SECCHI, Bernardo. Urbanisme et inégalités: La ville des riches et la ville des pauvres. MetisPresses, 2014.

SIDOU, J. M. Othon. Dicionário Jurídico: Academia Brasileira de Letras Jurídicas (6a edição). Rio de Janeiro: Forense Universitária, 2000. (Primeira edição em 1990).

SILVA, Rachel C. M. da. Ordem e irregularidade no espaço urbano: uma perspectiva regulatória. In: PINHAIRO MACHADO, D. (org.). Sobre Urbanismo. Rio de Janeiro: Viana \& Mosley; Ed. PROURB, 2006. pp.89-102. 